\title{
Proximal femoral geometry and its clinical relevance in Indians - A radiological study
}

\author{
Syed Imran Sultan ${ }^{1, *}$, D. S. Joshi ${ }^{2}$, C. V. Diwan ${ }^{3}$ \\ ${ }^{1}$ Assistant Professor, ${ }^{2,3}$ Professor \& HOD, Dept. of Anatomy, Dr. Shankarrao Chavan Government Medical \\ College, Nanded, Maharashtra, India
}

*Corresponding Author:

Email: drsyedimran86@gmail.com

\begin{abstract}
Introduction: Morphology and statistical analysis of proximal femoral anthropometry among different populations reveals a great amount of variation. Operations on the proximal femur are one of the commonest in orthopaedic surgical practice. The aim of these operations is to restore femoral anatomy to the normal as far as possible.

Aim: The aim of present study is to remove the lacunae of information about proximal femoral geometry in Indians and evaluate its impact on implant design.

Materials and Methods: 150 normal digital antero-posterior radiographs of pelvis with both hips (PBH) of patients were studied from the department of Radiology. The Neck Shaft angle, Neck Width and Neck Length were measured.

Result: The mean neck shaft angle in Male and Female femora was $133.3 \pm 6.83^{\circ}$ and $129.5 \pm 7.38^{\circ}$ respectively. The mean Neck length in Male and Female femora was $30.68 \pm 5.40 \mathrm{~mm}$ and $26.43 \pm 4.82 \mathrm{~mm}$ respectively. The mean Neck width in Male and Female cadaveric femora was $34.04 \pm 3.37 \mathrm{~mm}$ and $28.25 \pm 2.82 \mathrm{~mm}$ respectively. The mean Neck length in both Male and Female femora on both Right and Left sides showed significant positive correlation with the Neck width.

Conclusion: This study will help the biomechanical engineers in altering the implant designs to suit the needs of Indian Population.
\end{abstract}

Keywords: Neck length, Neck shaft angle, Neck width, Proximal femoral geometry.

Received: $20^{\text {th }}$ October, 2017

Accepted: 04 ${ }^{\text {th }}$ December, 2017

\section{Introduction}

Operations on the proximal femur are one of the commonest in orthopaedic surgical practice. The aim of these operations is to restore femoral anatomy to the normal as far as possible. ${ }^{1}$ The morphology of proximal femur is an essential parameter in the design and development of implant. Inappropriate implant design and size could affect outcome of the surgery with reported complications such as stress shielding, micromotion and loosening. The use of implants designed based on other populations posed at least two potential major issues. First and foremost is the difference of the anthropometry of the proximal femur between ethnics due to differences in lifestyle, physique, applied force and their distribution. Another issue is implantmorphology mismatch that might cause difficulties during implant placement and could lead to accelerated deterioration of the implant life thus affecting short-term and long-term outcome of the surgery. ${ }^{2}$ Most of Indian orthopaedics surgeons have felt the need for modification of the dimensions of these implants to suit Indian standards. ${ }^{3}$ So to minimize intra operative and postoperative complications, the implants should be designed by taking in to account anthropometry and biomechanics data. Thus the study conducted with aim to remove lacunae of information about proximal femoral geometry in Indian population and evaluate its impact on implant design.

\section{Materials and Methods}

150 normal digital antero-posterior radiographs of pelvis with both hips $(\mathrm{PBH})$ of patients were studied from the Department of Radiology. Of the 150 radiographs, 98 were of male and 52 were of female.

Inclusion and exclusion criteria: $\mathrm{PBH}$ radiographs of normal adult subjects were included. Radiographs of fractured femur, deformity of femur and of children were excluded from the study.

Measurements of neck shaft angle, neck length and neck width were taken on the digital radiographs using Dicom software.

Neck-shaft angle (NSA): It was measured on the digital radiographs by determining the axes through femoral shaft and femoral neck using Dicom software. For determining neck axis 2 lines were drawn, one at the narrowest point of 
neck and other the vertical diameter of head. Midpoints of both the lines were marked. Line passing through these 2 points represents the neck axis. Similarly, for determining shaft axis 2 horizontal lines were drawn on shaft, one below intertrochanteric line and other at mid shaft. Midpoints of both the lines were marked. Line passing through these 2 points represents the shaft axis. The angle between the neck axis and shaft axis is the neck shaft angle and was measured using Dicom software. (Fig. 1)

Neck length (NL): It was measured by drawing a straight line from the base of the greater trochanter to the inferior margin of the head using Dicom software. (Fig. 2)

Neck width (NW): It was measured as the least distance between upper and lower margins of the neck using Dicom software. (Fig. 3)
Measurements of Implants: Commonly used implants for fracture of proximal femur like Dynamic Hip Screw (DHS) and Proximal femoral nail were obtained from department of orthopedics and dimensions were noted.

\section{Statistical Analysis}

All the data was tabulated and was statistically analyzed using Graph pad software. The Mean, Standard deviation, Coefficient of variation were obtained for each variable with respect to sex, side and combined taken together. Unpaired t-test was applied for statistical significance. Also Pearson's correlation coefficient was calculated to show the correlation between different variables.

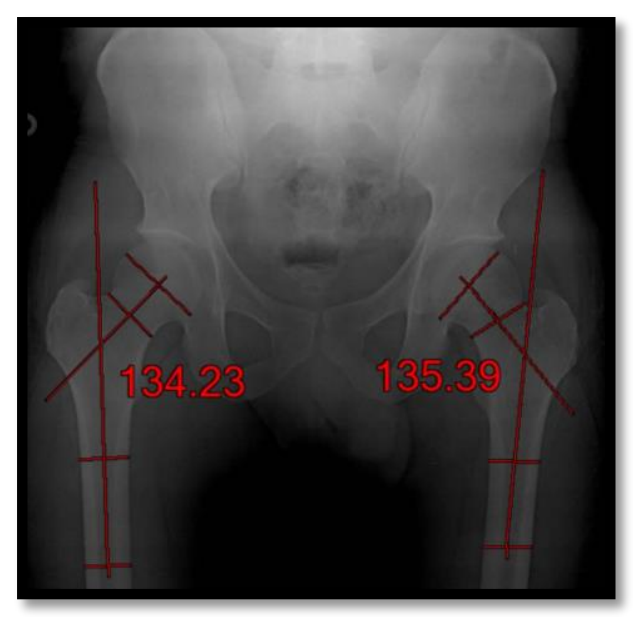

Fi. 1: Measurement of Neck Shaft Angle

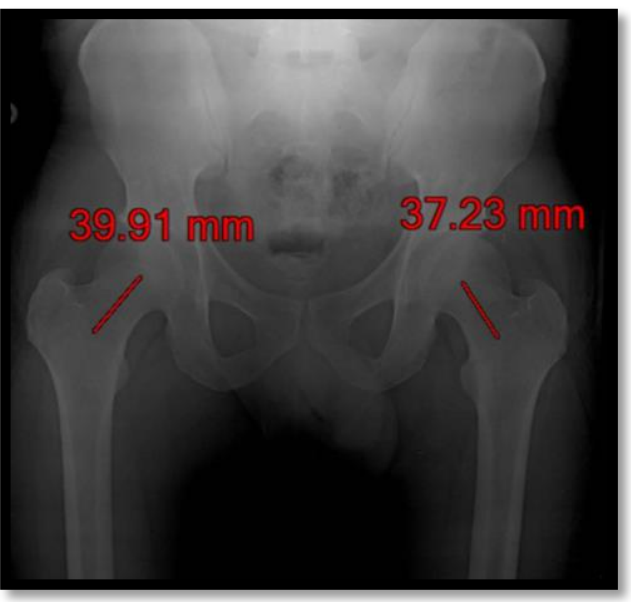

Fig. 2: Measurement of Neck Length

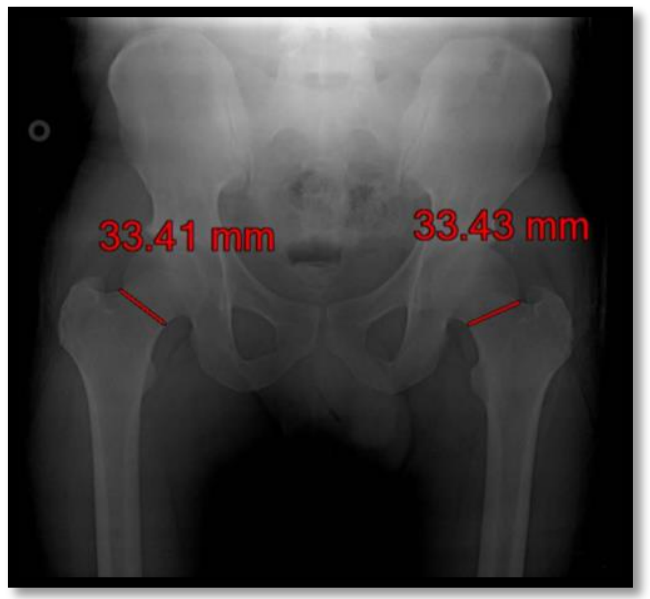

Fig. 3: Measurement of Neck Width

\section{Result}

The mean neck shaft angle in male femora was $133.3^{\circ}$ and in female femora was $129.5^{\circ}$ which is statistically significant. The mean neck length was $30.68 \mathrm{~mm}$ in male femora and $26.43 \mathrm{~mm}$ in female 
femora and its statistically significant. The mean neck width was $34.04 \mathrm{~mm}$ in male femora and 28.25 $\mathrm{mm}$ in female femora which is statistically significant.

Table 1: Mean NSA, NL, NW in Radiographs in Males and Females

\begin{tabular}{|l|c|c|c|}
\hline & Male & Female & p - value \\
\hline Mean Neck Shaft Angle & $133.3^{\circ} \pm 6.83^{\circ}$ & $129.5^{\circ} \pm 7.38^{\circ}$ & 0.0079 \\
\hline Mean Neck Length & $30.68 \pm 5.40$ & $26.43 \pm 4.82$ & 0.0001 \\
\hline Mean Neck Width & $34.04 \pm 3.37$ & $28.25 \pm 2.82$ & 0.0001 \\
\hline
\end{tabular}

The mean neck shaft angle is $132.4^{\circ}$ in right femora and $131.5^{\circ}$ in left femora and it is statistically not significant. The mean neck length is $29.69 \mathrm{~mm}$ in right femora and $32.26 \mathrm{~mm}$ in left femora which is statistically not significant. The mean neck width is $31.81 \mathrm{~mm}$ in right femora and 32.26 in left femora and it is statistically not significant.

Table 2: Mean NSA, NL, NW of Right and Left side in Radiographs

\begin{tabular}{|l|c|c|c|}
\hline & Right Femora & Left Femora & p- value \\
\hline Mean Neck Shaft Angle & $132.4^{\circ} \pm 7.48^{\circ}$ & $131.5^{\circ} \pm 6.99^{\circ}$ & 0.2458 \\
\hline Mean Neck Length & $29.69 \pm 5.79$ & $32.26 \pm 4.23$ & 0.1373 \\
\hline Mean Neck Width & $31.81 \pm 4.20$ & $32.26 \pm 4.23$ & 0.3728 \\
\hline
\end{tabular}

Table 3 shows that mean Neck shaft angle in both Male and Female femora, on both Right and Left side did not show significant correlation with mean Neck length. The mean Neck shaft angle in both Male and Female femora, on both Right and Left side did not show significant correlation with mean Neck width. The mean Neck length in both Male and Female femora on both Right and Left sides showed significant positive correlation with the Neck width.

Table 3: Correlation between NSA, NL, NW

\begin{tabular}{|c|c|c|c|c|c|c|c|c|}
\hline \multirow{2}{*}{$\begin{array}{c}\text { Correlation } \\
\text { Between }\end{array}$} & \multicolumn{3}{|c|}{ Male Radiographs } & \multicolumn{3}{c|}{ Female Radiographs } \\
\cline { 2 - 9 } & R value & $\mathrm{p}$ value & R value & $\mathrm{p}$ value & R value & P value & R value & $\mathrm{p}$ value \\
\hline NSA \& NL & 0.0103 & 0.9193 & -0.1652 & 0.1039 & -0.1297 & 0.3594 & -0.0606 & 0.6692 \\
\hline NSA \& NW & 0.0782 & 0.4437 & -0.1704 & 0.0934 & -0.1093 & 0.4401 & -0.0685 & 0.6292 \\
\hline NL \& NW & 0.2642 & 0.0085 & 0.3184 & 0.0013 & 0.3163 & 0.0223 & 0.2478 & 0.0464 \\
\hline
\end{tabular}

\section{Discussion}

The mean neck shaft angle in radiographs in the present study is $131.97^{\circ}$, which is higher than earlier Indian studies of Siwach, Deshmukh and Kaur with mean neck shaft angle of $123^{\circ}, 121^{\circ}$ and $121.26^{\circ}$ respectively. Also it is more than the mean neck shaft angle in studies by Otsianyi and Pires. Whereas it is less than earlier study of Mishra and Siaka.

Sexual difference, with respect to the neck-shaft angle in radiographs is observed in the present study. Mean neck-shaft angle in males is $133.3^{\circ}$, which was comparatively higher than in females with mean neck-shaft angle $129.5^{\circ}$. Similar higher values for males in comparison with females were observed by Kaur, Otsianyi, Baharuddin, Nissen.

Side difference with respect to the neck shaft angle is also noted in the present study. Right side femora had mean neck-shaft angle of $132.4^{\circ}$ which is comparatively more than on the left side $131.5^{\circ}$. This was observed in an earlier study by Kaur.

Table 4: Comparison of Mean Neck Shaft Angle in cadaveric femora

\begin{tabular}{|c|l|c|c|c|c|c|}
\hline \multirow{2}{*}{ S. No } & \multirow{2}{*}{ Author } & \multirow{2}{*}{ Year } & \multirow{2}{*}{ Region } & \multicolumn{3}{|c|}{ NSA (degrees) } \\
\cline { 5 - 6 } & & & & Mean & Male & Female \\
\hline 1 & Siwach et al. $^{1}$ & 2003 & India & $123^{\circ}$ & - & - \\
\hline 2 & Pulkinen et al. $^{4}$ & 2004 & Finland & - & - & $128.30^{\circ}$ \\
\hline 3 & Nissen et al. $^{5}$ & 2005 & Danish & - & $131^{\circ}$ & $129^{\circ}$ \\
\hline 4 & Irdesal et al. $^{6}$ & 2006 & Turkey & - & - & $131.50^{\circ}$ \\
\hline 5 & Saikia et al. $^{7}$ & 2008 & India & $139.50^{\circ}$ & - & - \\
\hline 6 & Mishra et al. $^{7}$ & 2009 & Nepal & $132.26^{\circ}$ & - & - \\
\hline \hline
\end{tabular}




\begin{tabular}{|c|c|c|c|c|c|c|}
\hline 7. & Deshmukh et al ${ }^{8}$ & 2010 & India & $131^{\circ}$ & - & - \\
\hline 8 & Otsianyi et al. ${ }^{9}$ & 2011 & Kenya & $127.56^{\circ}$ & $128.21^{\circ}$ & $126.11^{\circ}$ \\
\hline 9 & Baharuddin et al. $^{2}$ & 2011 & Malay & - & $132.33^{\circ}$ & $129.87^{\circ}$ \\
\hline 10 & Pires et al..$^{10}$ & 2012 & Brazil & $129.20^{\circ}$ & - & - \\
\hline 11 & Kaur P. et al. ${ }^{11}$ & 2013 & India & $\begin{array}{l}\text { Rt-121.39 } \\
\text { Lt-121.13 }\end{array}$ & $\begin{array}{l}\text { Rt-121.63 } \\
\text { Lt-121.33 }\end{array}$ & $\begin{array}{l}\text { Rt-121.16 } \\
\text { Lt-120.94 }\end{array}$ \\
\hline 12 & Present study & 2017 & India & $\begin{array}{r}131.97^{\circ} \\
\text { Rt- } 132.4^{\circ} \\
\text { Lt-131.5 }\end{array}$ & $133.3^{\circ}$ & $129.50^{\circ}$ \\
\hline
\end{tabular}

Radiologically, mean neck length in the present is 29.20 which is less when compared with Study of Pires ${ }^{10}$ in which mean neck length was $35.7 \mathrm{~mm}$.

The mean neck width in radiographs of femur taken together irrespective of sex and side is $32.03 \mathrm{~mm}$ which is comparatively Correlating with the studies of Siwach whereas it is less than the studies of Nissen, Mishra, and Pires and more than the study of Baharuddin.

Table 5: Comparison of Mean Neck Width in cadaveric femora

\begin{tabular}{|c|l|c|c|c|}
\hline S. No. & \multicolumn{1}{|c|}{ Author } & Year & Region $^{1}$ & $\begin{array}{c}\text { Mean Neck Width } \\
(\mathbf{m m})\end{array}$ \\
\hline 1 & Siwach et al. $^{1}$ & 2003 & India & 29.9 \\
\hline 2 & Nissen N et al. $^{5}$ & 2005 & Danish & R-38, L-33 \\
\hline 3 & A. K. Mishra $^{7}$ & 2009 & Nepal & 34.42 \\
\hline 4 & Baharuddin M. Y. $^{2}$ & 2011 & Malay & M-28.88 F-25.95 \\
\hline 5 & Pires et al. $^{10}$ & 2012 & Brazil & 36.6 \\
\hline 6 & Present study & 2017 & India & $\begin{array}{c}32.03 \\
\text { M-34.04 F-28.25 }\end{array}$ \\
\hline
\end{tabular}

In the present study, a positive correlation was seen between the neck length and neck width in males and females on both the sides which is statistically significant. Whereas there was no correlation between Neck shaft angle and Neck length in both males and females and on both sides as stated by Gujar et al. ${ }^{3}$

Table 6: Comparison between dimensions of Indian Femora and Implants

\begin{tabular}{|l|c|c|c|c|}
\hline & \multicolumn{2}{|c|}{ In Radiographs } & \multicolumn{2}{c|}{ In Implants } \\
\cline { 2 - 5 } & Right & Left & DHS $^{4}$ & Femoral Nail \\
\hline $\begin{array}{l}\text { Neck Shaft } \\
\text { Angle }\end{array}$ & $132.4^{0}$ & $131.5^{0}$ & $\begin{array}{c}125^{0}-150^{0} \\
135^{0} \text { commonly } \\
\text { used }\end{array}$ & $130^{0}$ \\
$135^{0}$ \\
\hline Neck Length & 29.69 & 28.73 & $\begin{array}{c}25 \mathrm{~mm} \text { (Short } \\
\text { barrel) } \\
38 \mathrm{~mm} \text { (long barrel) }\end{array}$ & - \\
\hline Neck Width & 31.81 & 32.36 & $24.8 \mathrm{~mm}$ & $\begin{array}{c}9.5 \mathrm{~mm} \text { and } \\
6.5 \mathrm{~mm}\end{array}$ \\
\hline
\end{tabular}

The Dynamic Hip screw is the implant of choice for stable trochanteric fractures. Higher angle implants causes malunion in valgus and that with lower angle causes malunion in varus thus altering the biomechanics of both at hip joint and knee joint. ${ }^{3}$

Ravichandran et al. ${ }^{3}$ stated that insertion of these screws needs reaming thus removing the available cancellous bone. Screws with large thread diameter occupy greater area in the neck and head of the femur and takes away viable cancellous bone. The thread diameter of DHS is
$12.5 \mathrm{~mm}$ and barrel diameter is $12.6 \mathrm{~mm}$. Insertion of this needs reaming upto $11.5 \mathrm{~mm}$ and tapping upto $13.5 \mathrm{~mm}$. Such implants would occupy most of the available space in the neck and would cause tamponade effect resulting in non union and avascular necrosis.

The transcervical region of neck is the narrowest portion of femoral neck. This is of particular importance while fixing the fracture neck femur with screw as large diameter screw may decancellate the neck to very large extent. ${ }^{7}$ 
Mishra et al. ${ }^{7}$ also concluded that western implants should be used only after careful consideration in Indians and also stresses that the fracture implant designs should be specific for Indian population.

Chiu et al. ${ }^{11}$ reported that the distance between the upper border of the anti-rotation pin and the lower border of the femoral neck screw is approximately $20 \mathrm{~mm}$. The margin of safety for placement of both the femoral neck screw and anti-rotational pin is approximately $5 \mathrm{~mm}(2.5 \mathrm{~mm}$ cranially and $2.5 \mathrm{~mm}$ caudally).

Although different size of same design generally are available from manufactures, there is little evidence that ethnic morphologic difference are taken into account in orthopedic implant design. This universal application may not cause major clinical problems in implants that are applied externally to the skeleton; however, problems do arise with implants that are applied internally to skeleton. This becomes obvious in fixation of fracture and hip prosthesis, where linear and angular configuration has to be considered. The implant device and prosthesis designed for western skeleton are generally large in size, their angles, orientations and thread length also mismatch the femora. To get rid of this problem is to fit the prosthesis or implants by removing more bone which decreases bone stock, increasing the risk of intra operative fractures and post operative complications. Implants that are designed by taking in to account anthropometric and bio mechanic data will help in designing patient specific implants thereby minimizing the complications. ${ }^{7}$

\section{Conclusion}

Numerous published studies have underlined the importance of a close fit between the femur and the implanted stem. The availability of geometry data describing the proximal femur allows guidelines to be developed for the functional dimension of femoral component. These anatomic data also allow assessment of the match between the shape of existing components and the proximal femur.

The design specifications of the currently available orthopedic implants do not show a $100 \%$ match with the anatomical dimensions of the Indian femora. This study will help the biomechanical engineers in altering the implant designs to suit the needs of Indian Population. application. Indian journal of Orthopaedics. 2003;37(4):247-51.

2. Baharuddin Mohd Yusof, Kadir Mohammed Rafiq Abdul, Zulkifly Ahmad Hafiz, Saat Azlin, Aziz Azian Abdul, Lee Muhammad Hisyam. Morphology Study of the Proximal Femur in Malay Population. Int. J. Morphol. 2011;29(4):1321-5.

3. Ravichandran D. et al. Proximal femoral geometry in Indians and its clinical applications. J. Anat. Sco. India. 2011;60(1):6-12

4. Kaur P., Mathew S. and George U. A study of neck shaft angle in the north-west Indian population on radiographs. International Journal of Basic and Applied Medical Sciences. 2013;3(3):9-15.

5. Nissen N, Hauge EM, Abrahamsen B, Jensen JEB, Mosikilde L and Brixen K. Geometry of the proximal femur in relation to age and sex: a cross-sectional study in healthy adult Danes. Acta Radiologica. 2005;5:508-14

6. K C Saikia ,S K Bhuyan, R Rongphas. Anthropometric study of the hip joint in Northeastern region population with computed tomography scan. Indian J Orthop. 2008;42:2606.

7. Mishra A. K.; Chalise P.; Singh R. P. \& Shah R. $\mathrm{K}$. The proximal femur - a second look at rational of implant design. Nepal Med. Coll. J. 2009, 11(4):278-80.

8. T.R. Deshmukh, A.M. Kuthe, D.S. Ingole and S.B. Thakre. Prediction of Femur Bone Geometry using Anthropometric Data of Indian Population: A Numerical Approach. Journal of Medical Sciences. 2010;10(1):12-18.

9. Caetano, E. B.; Serafim, A. G. \& Padoveze, E. H. Study of the Collo-diaphyseal Angle of the Femur of Corpses in the Anatomy Department of the PUC-SP Medical School. Int. J.Morphol.2007;25(2):285-8.

10. Pires RES, Prata EF, Gibram AV, Santos LEN, Lourenço PRBT, Belloti JC. Radiographic anatomy of the proximal femur: correlation with the occurrence of fractures. Acta Ortop Bras. 2012;20(2):79-83.

11. Chiu C. K.; Chan C. Y. \& Singh V. A. Is the femoral neck geometry adequate for placement of the proximal femoral nail in the Malaysian population? A review of 100 cases. Med. J. Malaysia. 2009;64(1):22-6.

\section{References}

1. Siwach R.C., Dahiya S. Anthropometric study of proximal femur geometry and its clinical 